\title{
Solid-liquid phase equilibria for aromatic compounds
}

\author{
M. Benkhennouf, K. Kamel and A. Dahmani \\ Laboratoire de Thermodynamique et Modélisation Moléculaire, Faculté de Chimie, \\ USTHB, BP. 32 El-Alia, 16111 Bab-Ezzouar, Alger, Algérie
}

\begin{abstract}
A Differential Scanning Calorimetry ( DSC 7, Perkin-Elmer) is used to determine the solidliquid phase diagram for polycyclic aromatic compounds of biphenyl and 2,3-dimethylnaphthalene. The eutectic temperature is also measured. In this work, the experimental diagram compared satisfactorily with group contribution models, Modified UNIFAC ( Lyngby and Dortmund versions ).
\end{abstract}

\section{INTRODUCTION}

Solubility of organic non-electrolyte systems is essential for the design and development of separation process involving crystallization. Polyaromatics components represent a technically important class of substances and are becoming increasingly important in the petroleum industry $[1,2]$.

The group contribution models (ASOG, UNIFAC) can be used to predict the thermodynamic properties. The basic data used for determining the interaction parameters are the VLE, $H^{\mathrm{E}}$ and infinite dilution activity coefficients. However in the absence of the required data, SLE measurements can be used to obtain such interaction parameters.

The purpose of this paper is the determination of the phase diagram of this mixture in term of UNIFAC ( Modified versions ) [3,4].

\section{EXPERIMENTAL}

\subsection{Materials}

2,3-dimethylnaphthalene (BDH, England ) and biphenyl. (Fluka, purity greater than 99 mol \%) were used without further purification.

\subsection{Apparatus and Procedure}

The sample was heated very slowly inside a glass cell at near the melting temperature of the major component. The liquified sample with continuous stirring was solidified, then a small amount of solid was taken and sealed in a DSC cell. The DSC apparatus ( DSC 7,Perkin-Elmer) was used in this study.

\section{RESULTS AND DISCUSSION}

A typical DSC curve obtained is shown in figure 1. The system is eutectic because the first peak appeared at the constant temperature. 

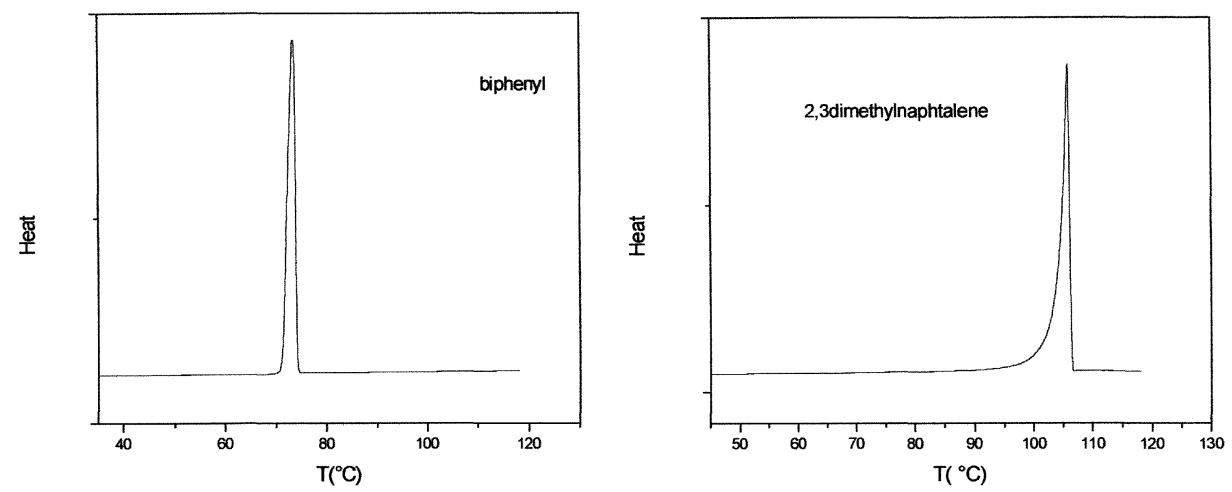

Figure 1: DSC thermogram of biphenyl and 2,3-dimethylnaphthalene.

Experimental DSC measurements gives the values of $\Delta \mathrm{H}_{\mathrm{f}}(\mathrm{J} / \mathrm{g})=124.94$ and 123.54 and the melting point $\mathrm{T}_{\mathrm{f}}=71,19$ and $104,37^{\circ} \mathrm{C}$ respectively for biphenyl and 2,3-dimethylnaphtalene are in good agreement with literature data $[5,6]$.

The DSC curve of 2,3-dimethylnaphthalene + biphenyl mixture at different compositions have been determined in order to obtain the phase diagram of the system. It is characterized by an eutectic point for $x_{E}=0.66$ and $\mathrm{t}_{\mathrm{E}}=58.4^{\circ} \mathrm{C}$. We have reported in figure 2 the DSC thermogram of the mixture at $x_{I}=0.10$ and $x_{I}=0.199$ respectively.

The original UNIFAC only predicts $G^{\mathrm{E}}$, whereas the modified UNIFAC, Larsen et al.[3], and Gmehling [4] can be used to predict $G^{\mathrm{E}}, H^{\mathrm{E}}$, and $\gamma_{i}^{\infty}$ and SLE. Values of the required geometrical and interaction parameters of 2,3-dimethylnaphthalene + biphenyl have been given elsewhere [3,4].
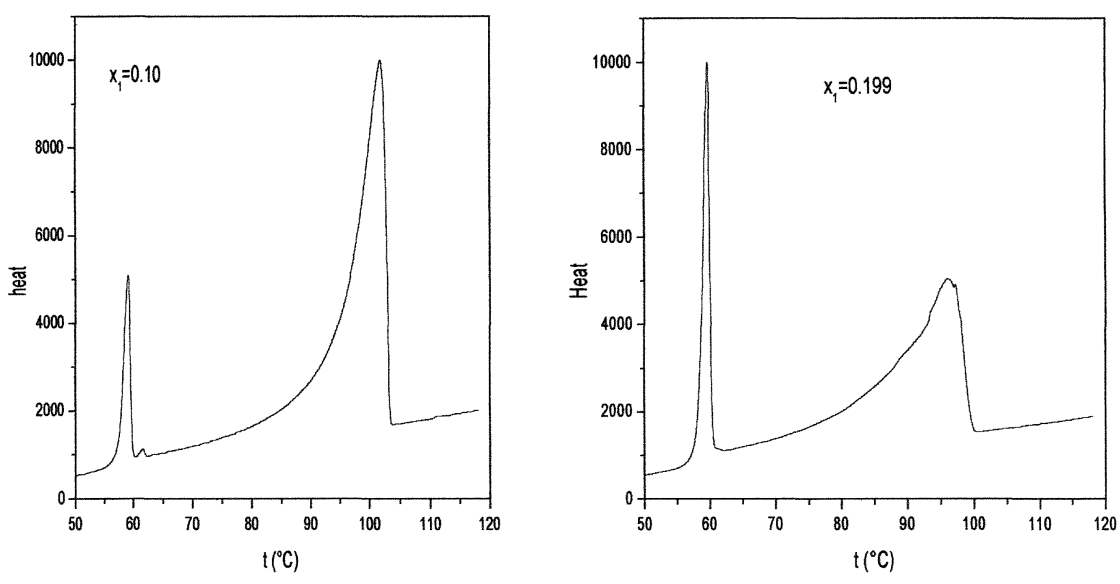

Figure 2: DSC thermogram biphenyl (1) + 2,3- dimethylnaphthalene (2) mixture. 
The solid-liquid phase diagrams with simple eutectic is given by the following equation (Prausnitz 1969) :

$$
\operatorname{Ln} x_{i}+\operatorname{Ln} \gamma_{i}+\left(\Delta H_{i}^{f} / R\right)\left(1 / T-1 / T_{i}^{f}\right)-\left(\Delta C_{p i}^{f} / R\right)\left(\operatorname{Ln}\left(T_{i}^{f} / T\right)+T_{i}^{f} / T-1\right)=0
$$

Where $\Delta H_{i}^{f}, \Delta C_{p i}^{f}, T_{i}^{f}$, are respectively the molar heat of fusion, the molar heat capacity of fusion and the melting temperature of component $i$ and $\gamma_{i}$ the activity coefficient of component $i$.

The agreement between the measured data and the calculated SLE assuming ideal solution are good. A graphical comparison between calculated SLE phase diagrams and experimental data is shown in Fig.3. The overall satisfactory agreement between experimental and calculated diagrams provides that the group contribution model can be used with a good accuracy to predict the solidliquid diagram.

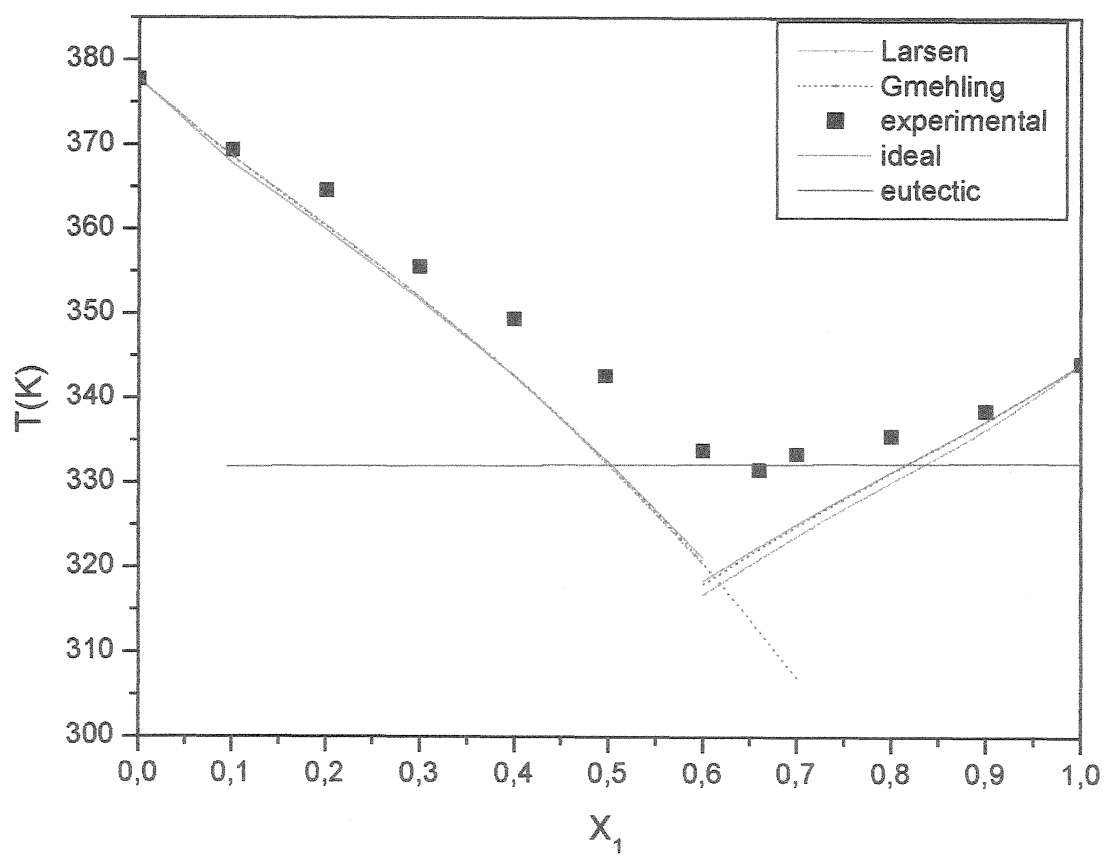

Figure 3: Determined and calculated SLE for biphenyl (1) + 2,3- dimethylnaphthalene (2) mixture.

\section{References}

1. W.B. Sediawan, S. Gupta, E. Mclaughlin, J. Chem. Eng. Data, 34 (1989).

2. H. Knapp, M. Teller, R. Langhorst, Chemistry Data Series; Dechema: Frankfurt, 1987;Vol. VIII, Part 1.

3. B. L. Larsen, P. Rasmussen, Aa. Fredenslund, Ind. Eng. Chem. Res., 26 (1987).

4. J. Gmehling, J. Li, M. Schiller, Ind. Eng. Chem. Res., 32 (1993).

5. A. Gupta, E. Mclaughlin, J. Chem. Eng. Data, 39 (1994).

6. M.E. Spaght, S. B. Thomas, G.S. Parks, J. Phys. Chem, 36 (1932). 
